Dicle Tıp Dergisi / Dicle Med J (2019) 46 (3) : 543 - 551

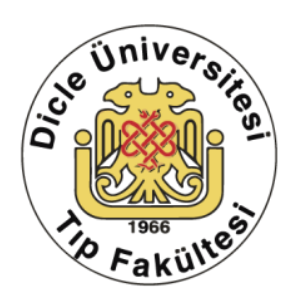

wWW.diclemedj.org

Özgün Araștırma / Original Article

\title{
Klinik Örneklerden İzole Edilen Aspergillus Türlerinin Tanımlanmasında Geleneksel Yöntemler, MALDI-TOF MS ve Dizi Analizi Yöntemlerinin Karşılaştırılması
}

\author{
Esma Akkoyun Bilgi' ${ }^{1}$ Nuri Kiraz² \\ 1 Sağllk Bilimleri Üniversitesi Kocaeli Derince Eğitim ve Araștırma Hastanesi Kocaeli, Türkiye ORCID: 0000-0002-6785-521X \\ 2 Tekirdağ Namık Kemal Üniversitesi Mikrobiyoloji Anabilim Dalı Tekirdağ, Türkiye ORCID: 0000-0001-7415-190X
}

Geliş: 27.05.2019; Revizyon: 14.07.2019; Kabul Tarihi: 29.07.2019

$\ddot{0} \mathbf{z}$

Amaç: Aspergillus türü mantar enfeksiyonları immün sistemi baskılanmıș hastalarda, yüksek mortalite ve morbidite ile sonuçlanan invazif hastalıklara yol açmaktadır. Bu nedenle hızlı ve doğru tanı konularak uygun antifungal tedavi başlanması invazif aspergillozlu hastalar için hayati öneme sahiptir. Günümüzde daha hızlı, kolay uygulanabilir, yüksek duyarlılık ve özgüllüğe sahip yeni tanı yöntemleri tercih edilmektedir. Bu çalışmada çeşitli klinik örneklerden izole edilen Aspergillus türlerinin; geleneksel yöntemler, MALDI-TOF MS sistemi ve DNA dizi analizi yöntemi kullanılarak tanımlanması ve bu yöntemlerin karşılaştırılması amaçlanmıştır.

Yöntemler: Bu çalışmada çeşitli klinik örneklerden izole edilen toplam 50 Aspergillus izolatı çalışmaya dahil edildi. Aspergillus suşlarından 2 tanesi kontaminasyondan dolayı çalışma dışı bırakıldı.

Bulgular: Çalışmamızda referans tanımlama yöntemi olarak kullandığımız ITS bölgesinin dizi analiziyle, suşların 25 tanesi A.fumigatus tür kompleksi $(\% 52,08), 17$ 'si A.flavus tür kompleksi $(\% 35,42)$, 3'ü A.niger tür kompleksi $(\% 6,25)$, 2'si A.terreus tür kompleksi $(\% 4,17), 1$ 'i A.sydowii tür kompleksi $(\% 2,08)$ olarak tanımlandı. Altın standart yöntemin dizi analizi olduğu ve geleneksel yöntem ile karşılaştırıldığında \%97,9 uyum olduğu gözlendi. İki farklı yazılım kullandığımız MALDI-TOF MS sisteminde ise güncel IVD (invitro diagnostik) VITEK MS V.2.0 yazılımı ile doğru tanımlanan köken 37(\%77,1) iken SARAMIS 4.12 RUO yazılımı ile doğru tanımlanan köken 42(\%87,5) olarak bulundu.

Sonuç: Moleküler yöntemler, geleneksel yöntemlerin yetersiz kaldığı ve tür tanımının yapılamadığı durumlarda tamamlayıcı yöntem olarak kullanılabilir. Zaman açısından değerlendirildiğinde MALDI-TOF yöntemi hızlı ve duyarlı bir yöntem olmasına rağmen veri tabanının geliştirilmesi amacıyla suş sayısının arttırılarak bu tür çalışmaların tekrarlanması gerekir.

Anahtar kelimeler: Aspergillus, MALDI-TOF, Kütle spektrometri, ITS dizi analizi, konvansiyonel yöntem.

DOI: $10.5798 /$ dicletip.620589

Yazışma Adresi / Correspondence: Esma Akkoyun Bilgi, Sağlık Bilimleri Üniversitesi Kocaeli Derince Eğitim ve Araştırma Hastanesi Kocaeli, Türkiye e-mail: esma.akkoyun@hotmail.com 


\title{
Comparison of Conventional Methods, MALDI-TOF MS and Sequence Analysis Methods for Identification of Aspergillus Species Isolated from Clinical Samples
}

\begin{abstract}
Objective: Fungal infections associated with Aspergillus species cause invasive diseases leading high mortality and morbidity as a result of deficiency of primary defence systems in immunosuppressive patients. Therefore, starting appropriate antifungal treatment after rapid and accurate diagnosis is critically important for invasive aspergillosis patients. Nowadays, more rapid, easily applicable, having high sensitivity and specifity new diagnostic methods are required. In this study, identification of Aspergillus spp. isolated from various clinical samples by using conventional methods, MALDI-TOF MS system and DNA sequence analysis and comparison of the methods are aimed.

Methods: Totally 50 Aspergillus strains were included in this study. Two isolates were excluded from the study due to contamination.

Results: 25 strains were identified as A.fumigatus species complex (52.08\%), 17 strains were identified as A.flavus species complex (35.42\%), 3 strains were identified as A.niger species complex (6.25\%), 2 strains were A.terreus species complex (4.17\%) and 1 strain was A.sydowii species complex (2.08\%) byITS sequence analysis method used as reference diagnostic method in this study. The sequence analysis wasthe gold standard method and it was observed that there was $97.9 \%$ compliance compared to the conventional method. Two different software programmes were used for MALDI-TOF MS system. 37 strains (77.1\%) were accurately defined by current IVD (in vitro diagnostic) VITEK MS V.2.0 whereas 42 strains (87.5\%) were accurately defined by SARAMIS 4.12 RUO software programme.

Conclusions: Molecular methos are thought to be appropriate to be used as complementary method when conventional methods are insufficient for identification at the species level. Although MALDI-TOF MS method is rapid and sensitive method when evaluated in terms of time, it is concluded that such studies should be repeated with more strains to develop database.
\end{abstract}

Keywords: Aspergillus, MALDI-TOF, Mass Spectrophotometry, ITS sequence analysis, conventional method.

\section{GíRIŞ}

Aspergillus, insanlarda immün sistemin durumuna göre zararsız bir kolonizasyondan, akut invazif hastalık gibi geniş bir yelpazede farklı klinik enfeksiyonlara neden olabilir ${ }^{1-3}$. İnvazif Aspergillus enfeksiyonlarının, özellikle derin nötropenik ve hematolojik maligniteli hastalar olmak üzere, bağışıklık sistemi baskılanmış kişilerde yüksek mortalite ve morbidite oranı nedeniyle erken tanı ve tedavisi önemlidir1,4,5. Aspergillus'un tür düzeyinde tanımlanması, türlerin farklı direnç paternleri nedeniyle klinik olarak önem arz etmektedir. Rutin laboratuarların çoğu, küf mantarlarının tanımlanması için makroskopik ve mikroskopik morfolojik özellikleri kullanmaktadır. Bu nedenle çoğu klinik izolat tür kompleksi düzeyinde tanımlanmaktadır. Antifungal tedavinin etkinliği, hızlı ve tür düzeyinde doğru tanımlama ile artmaktadır6. Son ylllarda kimyasal spektroskopik ve kütle analizi yöntemlerinin mikolojik tanımlamada kullanımı artmıştır ${ }^{7,8}$. MALDI-TOF MS (Matriks Aracılı Lazer Dezorpsiyon Iyonizasyon- Uçuş Zamanı-Kütle Spektrometresi) yöntemi mayaların tanımlanması amacıyla kullanılan yüksek duyarlıklı,hızlı ve maliyeti düşük bir sistemdir ${ }^{1,8-10 .}$

MALDI-TOF MS yönteminde, mikroorganizmalara ait proteinlerin lazer atışları ile iyonizasyonu yapıldıktan sonra elektromanyetik uçuş tüpünden geçirilir. İyonlar kütleleriyle orantılı hız kazanarak detektöre farklı zamanda çarpmaları ile kaydedilen sinyaller proteinlerin kütle spektrumlarını oluşturur. Görüntülenen spektrum, mevcut veri tabanındaki 
spektrumlarla karşılaștırılarak, hem cins hem de tür bazında tanımlama yapılır 9,10,11,12.

MALDI-TOF MS yöntemi ilemantarların tür bazında doğru olarak tanımlanma oranı, özellikle Candida cinsinde daha yüksekken, dermatofitler, Aspergillus, Penicillium ve Fusarium cinsi mantarlar da, referans spektrum yetersizliği nedeniyle daha az oranda tanımlandığı bildirilmiştir 5,10 Son zamanlarda MALDI-TOF MS yöntemi kullanılarak Aspergillus türleri ile çeşitli çalışmalar yapılarak referans spektrum genişletilmeye çalışılmaktadır ${ }^{1,4,5,12,13}$. Bu çalışmada çeşitli klinik örneklerden izole edilen Aspergillus türlerinin, DNA dizi analizi altın standart yöntem olarak alınarak; geleneksel yöntemler ve MALDI-TOF MS sistemi kullanılarak tanımlanması ve bu yöntemlerin karşılaştırılması amaçlanmıştır.

\section{YÖNTEMLER}

Bu çalışmaya İstanbul Üniversitesi Cerrahpaşa Tıp Fakültesi, Enfeksiyon Hastalıkları ve Klinik Mikrobiyoloji laboratuvarı ve Osmangazi Üniversitesi Tıp Fakültesi Tıbbi Mikrobiyoloji Anabilim Dalı laboratuarında çeşitli klinik örneklerden izole edilen toplam 50 Aspergillussuşudahil edildi.

Çalışmada kullanılacak suşlar için İstanbul Üniversitesi Cerrahpaşa Tıp Fakültesinden 14.03.2014 tarihinde83045809/604/02-6879 sayı numarası ile etik kurul onayı alındı.

\section{Geleneksel Tanı Testleri}

Sabouraud dekstroz agar (SDA) besiyerinde üreyen küf kolonilerini saf olarak elde etmek, izolasyon ve identifikasyon işlemlerini sağlıklı yapabilmek için her koloniden çengel öze ile bir miktar örnek alınarak, Malt extractagar ve Czapek-Doxagara eşzamanlı batırma ekimleri yapıldı. Yine aynı koloniden çengel öze ile örnek alındı ve mantar stoğu oluşturmak için, önceden hazırlanan içinde gliserollü brucella broth besiyeri olan eppendorf tüplere konuldu. $\mathrm{Bu}$ şekilde hazırlanan bütün stok eppendorf tüpler daha sonra MALDI-TOF MS ve dizi analizi çalışmak üzere $-20^{\circ} \mathrm{C}^{\prime}$ ye kaldırıldı.

Aspergillus tür komplekslerinin ayrımı için Malt extractagar ve Czapek-Doxagarda üreyen küf kolonileri makroskobik olarak değerlendirildi. Makroskobik olarak koloninin dokusu kadifemsi, pamuksu, tozlu veya yünsü olabilmektedir. Koloni ön yüzünün rengi türe göre değişmekle birlikte; yeşil, sarı, turuncu, kahverengi veya siyah tonlarında görünebilmektedir. Üreyen küf kolonilerini mikroskobik olarak değerlendirmek için laktofenollü pamuk mavisi boyası ile preparat hazırlandi.

$\mathrm{Bu}$ hazırlanan preparat mikroskop altında bakılarak sterigmata (konidyojen hücre) sayısı, vezikül yapısı, fiyalitlerin tek-çift sıralı oluşu ve yerleşimi ayrıca konidyoforların yapısı ve rengi gibi ayrıntıları incelenerek identifikasyonları yapılan Aspergillus'lar tür komplekslerine ayrıldı. MALDI-TOF MS ve moleküler biyolojik bir yöntem olan ITS1- ITS2 bölgelerinin dizi analizi için $-20^{\circ} \mathrm{C}^{\prime}$ ye kaldırılan stoktaki izolatlar SDA besiyerine pasajlanarak tanımlama işlemleri gerçekleştirildi.

\section{MALDI-TOF MS Yöntemi ile İdentifikasyon}

Çalışma öncesi Aspergillus izolatları SDA besiyerinde canlandırıldı. Çalışmada 1,5 ml'lik eppendorf tüplerden her birine $50 \mu \mathrm{l}$ trifluoroaceticacid (Sigma-Aldrich) konulup üzerine $10 \mu \mathrm{l}$ 'lik plastik steril özenin tamamını kaplayacak şekilde alınan küfün sporlarından eklendi ve vortekslendi. Bu șekilde 30 dakika beklendi. Sonra bu karıșımın üzerine $450 \mu \mathrm{l}$ DNase ve RNasefree su eklenip vortekslendi. Cihaz için tasarlanmış 48 bölümlük test plağına her 16 bölümün ortasındaki bölüme pasajlanmış E. coli ATCC 8739 standart suşu bölüm dışına taşırılmayarak ince bir film tabakası oluşturacak şekilde yayıldı. Sonra diğer 48'lik bölüme her bir izolat için taze hazırlanan karışımlardan 1'er $\mu$ l eklendi ve oda sicaklığında kurutuldu. Kuruyan her bir bölümün üzerine matriks çözeltisi olarak $1 \mu \mathrm{L}$ 
VITEK MS-CHCA (= $\alpha$-cyano-4-hydroxycinnamic acid) eklendi ve tekrar oda sıcaklığında kurutuldu. Plağın cihaza yüklenmesinin ardından, MALDI-TOF MS kütle spektrumlarında peptit ve protein profili iyi bilinen, taze pasajlanmış E. coli ATCC 8739 standart suşu kullanılarak cihazın otomatik kalibrasyonu ve kontrolü yapıldıktan sonra değerlendirilme başladı. Plak üzerinde yer alan 48 örnek toplu olarak çalışıldı.

Çalışmamızda MALDI-TOF MS sistemi olarak VITEK MS (Biomerieux, France) ticari sistemi kullanıldı. Ölçümler üretici firmanın önerdiği ayarlar ile yapıldı. Tüm izolatlardan elde edilen spektrumlar önce güncel IVD (invitrodiagnostik) VITEK MS V.2.0 yazılımı kullanılarak analiz edildi. IVD VITEK MS V.2.0 yazılımı ile tanımlanamayan türler için çalışma tekrar edilerek sadece araştırma amaçlı kullanilan SARAMIS 4.12 RUO (ResearchUse0nly) yazılımı kullanılarak değerlendirildi.

\section{DNA Dizi Analizi İle Tanımlama}

a. Genomik DNA İzolasyonu (Ekstraksiyon) : Örneklerden DNA eldesi GeneJETGenomik DNA Pürifikasyon Kiti (Thermo Scientific, ABD) ile üreticinin önerileri doğrultusunda yapıldı.

b. PCR ile DNA Amplifikasyonu: PCR ile ribozomal alt üniteye ait ITS1 ve ITS2 gen bölgeleri, ITS1 (5'-TCCGTAGGTGAACCTGCGG3') ve ITS4 (5'-TCCTCCGCTTATTGATATGC-3') primerleri kullanılarak çoğaltıldı.

Reaksiyon, PCR karışımı hazırlanılarak ABI 9700 GeneAmp PCR System (life sciences, USA) cihazında gerçekleştirildi. PCR sonrası oluşan ürünler \%1,5'luk agaroz jel elektroforezi ile kontrol edildi. Pozitif bantlar kolon tabanlı High Pure PCR Purification Kit (Roche, Almanya) ile saflaştırıldı ve sonrasında çift yönlü DNA dizi işlemi yapıldı.

\section{Dizi Analizi PCR}

DNA dizi analizi reaksiyonu, BigDyeSequencing kit kullanılarak çift yönlü olarak gerçekleştirildi. Döngü için ABI 9700 GeneAmp PCR System (life sciences, USA) cihazı kullanıldı.

Dizileme sonrası oluşan ürünler sephadexG-50 fine ile saflaştırıldıktan sonra Applied Biosystems 3130 Genetic Analyzer cihazında, POP-7 polimeri ve 36 cm'lik kapiller kullanılarak kapiller elektroforez işlemine tabii tutuldu. Elde edilen elektroferogramlarin analizi Sequencing Analysis programı ile gerçekleștirildi.

Dizi analizi verileri "National Center for Biotechnology Information (Bethesda, ABD) BLAST sistemi (http:// www.ncbi.nlm.nih.gov/BLAST/) kullanılarak analiz edildi ve suşlar türkompleksi düzeyinde tanımlandı.

\section{BULGULAR}

Klinik örneklerin 23'ü $(\% 47,9)$ balgam, 11'i $(\% 22,9)$ endotrakeal aspirasyon (ETA), 7'si $(\% 14,7)$ bronkoalveolar lavaj (BAL), 4'ü $(\% 8,3)$ doku, 2'si $(4,2)$ aspirasyon sivisı ve 1'i $(\% 2,8)$ sürüntüden izole edildi.

\section{Geleneksel Yöntem ile Tanımlama Sonuçları}

Örneklerin geleneksel yöntem ile tanımlanmasında Aspergillus suşlarının 25'i $(\% 52,1)$ A.fumigatus tür kompleksi, 17'si $(\% 35,4)$ A.flavus tür kompleksi, 3'ü $(\% 6,3)$ A.niger tür kompleksi, 2'si $(4,2)$ A.terreus tür kompleksi ve 1'i $(\% 2,1)$ Aspergillussp olarak tanımlandı.

\section{Dizi Analizi Sonuçları}

Çalışmamızda referans yöntem olarak kullandığımız ribozomal DNA ITS bölgesi dizi analiziyle, örneklerin 25'inde (\%52,1) A.fumigatus tür kompleksi, 17 'sinde $(\% 35,4)$ A.flavus tür kompleksi, 3'ünde $(\% 6,3)$ A.niger tür kompleksi, 2'sinde A.terreus tür kompleksi, 1 'inde $(\% 2,1)$ A.sydowii tür kompleksi olarak tanımlandı (Tablo 1). 
Tablo 1: Dizi analizi, Geleneksel ve MALDI-TOF MS yöntemiyle tanımlanan Aspergillus suşlarının dağılımı.

\begin{tabular}{|c|c|c|c|}
\hline No & Dízí & GELENEKSEL & MALDI-TOF \\
\hline 1 & A. fumigatus & A. fumigatus & A. fumigatus \\
\hline 2 & A. fumigatus & A. fumigatus & A. fumigatus \\
\hline 3 & A. niger & A.niger & Tanımlamadı \\
\hline 4 & A. fumigatus & A. fumigatus & A. fumigatus ${ }^{\mathbf{a}}$ \\
\hline 5 & A. flavus & A. flavus & A. flavus \\
\hline 6 & A. flavus & A. flavus & A. flavus \\
\hline 7 & A. fumigatus & A. fumigatus & A. fumigatus \\
\hline 8 & A. fumigatus & A. fumigatus & A. fumigatus \\
\hline 9 & A. flavus & A. flavus & A. flavus \\
\hline 10 & A. fumigatus & A. fumigatus & A. fumigatus \\
\hline 11 & A. fumigatus & A. fumigatus & A. fumigatus \\
\hline 12 & A. flavus & A. flavus & A. flavus \\
\hline 13 & A. terreus & A.terreus & A.terreus \\
\hline 14 & A. flavus & A. flavus & A. flavus \\
\hline 15 & A. fumigatus & A. fumigatus & A. fumigatus \\
\hline 16 & A. fumigatus & A. fumigatus & A. fumigatus \\
\hline 17 & A. fumigatus & A. fumigatus & A. fumigatus \\
\hline 18 & A. fumigatus & A. fumigatus & A. fumigatus \\
\hline 19 & A. flavus & A. flavus & A. flavus \\
\hline 20 & A. fumigatus & A. fumigatus & A. fumigatus \\
\hline 21 & A. fumigatus & A. fumigatus & A. fumigatus \\
\hline 22 & A. fumigatus & A. fumigatus & A. fumigatus \\
\hline 23 & A. fumigatus & A. fumigatus & A. fumigatus \\
\hline 24 & A. niger & A.niger & Tanımlamadı \\
\hline 25 & A. fumigatus & A. fumigatus & A. fumigatus ${ }^{\mathbf{b}}$ \\
\hline 26 & A. fumigatus & A. fumigatus & A. fumigatus \\
\hline 27 & A. fumigatus & A. fumigatus & A. fumigatus \\
\hline 28 & A. fumigatus & A. fumigatus & A. fumigatus ${ }^{\mathbf{a}}$ \\
\hline 29 & A. terreus & A.terreus & A.terreus $^{\mathbf{a}}$ \\
\hline 30 & A. flavus & A. flavus & A. flavus \\
\hline 31 & A. flavus & A. flavus & A. flavus $\mathbf{c}$ \\
\hline 32 & A. fumigatus & A. fumigatus & A. fumigatus \\
\hline 33 & A. flavus & A. flavus & A. flavus \\
\hline 34 & A. flavus & A. flavus & A. flavus \\
\hline
\end{tabular}

\begin{tabular}{|c|c|c|c|}
\hline 35 & A. fumigatus & A. fumigatus & A. sydowii \\
\hline 36 & A. fumigatus & A. fumigatus & A. fumigatus \\
\hline 37 & A. fumigatus & A. fumigatus & A. fumigatus \\
\hline 38 & A. flavus & A. flavus & Tanımlamadı \\
\hline 39 & A. flavus & A. flavus & A. flavus \\
\hline 40 & A. flavus & A. flavus & A. flavus \\
\hline 41 & A. flavus & A. flavus & A. flavus ${ }^{\mathbf{a}}$ \\
\hline 42 & A. flavus & A. flavus & A. flavus \\
\hline 43 & A. fumigatus & A. fumigatus & A. fumigatus ${ }^{\mathbf{a}}$ \\
\hline 44 & A. fumigatus & A. fumigatus & A. fumigatus \\
\hline 45 & A. niger & A. niger & Tanımlamadı \\
\hline 46 & A. sydowii & Aspergillussp. & A. fumigatus \\
\hline 47 & A. flavus & A. flavus & A. flavus \\
\hline 48 & A. flavus & A. flavus & A. flavus \\
\hline
\end{tabular}

aSARAMIS 4.12 RUO Yazılımı ile tanımlandı, b A. fumigatus/oryzae olarak tanımland,, c A. flavus/oryzae olarak tanımlandı.

\section{MALDI-TOF MS ile Tanımlama Sonuçları}

MALDI-TOF MS sisteminde güncel IVD VITEK MS V.2.0 yazılımı kullanılarak 48 köken çalışıldı. Çalışılan 48 kökenin 39'u $(\% 81,2)$ tanımlanırken 9'u $\quad(\% 18,8)$ tanımlanamadı. Tanımlanan 39 örnekten 2 köken $(\% 5,1)$ tür bazında DNA dizi analiz sonucu ile uyumsuz biçimde yani yanlış tanımlandı. Kalan 37 örnekten 2 köken de yine DNA dizi analiz sonucu ile opsiyonlu olarak (A.flavus/oryzae ve A.fumigatus/oryzae) tanımlandı ve doğru tanımlandığı kabul edildi. Yani VITEK MS V.2.0 yazılımı ile doğru tanımlanan köken 37 (\%77,1) olarak bulundu (Tablo 1).

IVD VITEC MS V.2.0 yazılımı ile tanımlanamayan 9 köken yanlış tanımlanan 2 köken ve opsiyonlu olarak tanımlanan 2 köken için çalışma, daha geniş kütüphaneye sahip ve araştırma için tasarlanmış olan SARAMIS 4.12 RUO yazılımı tekrar edilerek değerlendirildi. VITEC MS V.2.0 yazılımı ile yanlış tanımlanan 2 köken ve opsiyonlu olarak tanımlanan 2 köken ile de aynı sonuçlar elde edildi. SARAMIS 4.12 
RUO yazılımı; tanımlanamayan 9 kökenden 4 kökeni hiç tanımlayamazken 5 kökeni dizi analizi ile uyumlu olarak tanımladı.

MALDI-TOF MS sisteminde her iki yazılımla 2 köken A.flavus/oryzae ve A.fumigatus/oryzae olarak opsiyonlu tanımlanırken; 3 A.niger ve 1 A.flavus kökeni tanımlanamadı ve 2 köken DNA dizi analizi ile karşılaștırınca yanlış tanımlandı(Tablo I).

Geleneksel yöntem ve DNA dizileme sonuçları karşılaştırıldığında \%97,9 uyum olduğu gözlenmesine karşın MALDI-TOF MS sisteminde her iki yazılım kullanılarak 4 kökeni $(\% 8,3)$ tanımlanamazken 44 köken $(\% 91,6)$ tanımland.. MALDI-TOF MS sisteminin her iki yazılım kullanılarak tanımladığı 44 kökenden 2 'sinin $(\% 4,5)$, altın standart olarak kabul edilen dizi analizi sonuçları ile karşılaştırıldığında uyumsuz olduğu görüldü. MALDI-TOF MS sistemi ile tanımlaması yapılan 48 kökenden 42'sinin $(\% 87,5)$ DNA dizi analiz sonuçları ile karşılaştırıldığında doğru tanımlandığı gözlendi (Tablo 1 ).

\section{TARTIŞMA}

İmmunyetmezlikli hastalarda sistemik mantar enfeksiyonlarının mortalite oranın yüksek olması nedeniyle erken tanı ve tedavi önemlidir ${ }^{14-16}$. Riskli hasta gruplarında mantar enfeksiyonlarının tanısında direkt mikroskobik inceleme, boyalı preparatlar ve kültür yöntemleri tanıdaki önemini koruyan standart geleneksel yöntemlerdir ${ }^{1,2}$.

Son yıllarda mantar hastalıklarının sıklığının giderek artması ve ampirikantifungal kullanımının yaygınlaşması, dirençli mantar suşlarının ortaya çıkmasına ve direnç oranlarının artmasına neden olmaktadır. Bu nedenle tür düzeyinde identifikasyon önem taşımaktadır. İdentifikasyon için,direkt mikroskopi, histopatoloji ve kültür şiddetle tavsiye edilmektedir6,17.

Erken tanı için günümüzde daha hızlı, kolay uygulanabilir, yüksek duyarlılık ve özgüllüğe sahip yeni tanı yöntemlerine ihtiyaç duyulmaktadır ${ }^{1,5,18}$.

Yapılan çalışmalarda, pozitif mantar kültürü saptanan hastalarda invazif Aspergillusen feksiyonlarının, Candida enfeksiyonlarından sonra, en sık saptanan fungal enfeksiyonlar olduğu bildirilmiștir ${ }^{5,19}$.

Hastane kaynaklı aspergilloz olgularından genellikle A.fumigatus ve A. flavus 'un izole edildiği, son yllarda A. niger ve A. terreusenfeksiyonlarında artış olduğu bildirilmiştir ${ }^{1}$. Aspergillus enfeksiyonlarında solunum yolu örneklerinde daha çok A. fumigatus, yara yeri enfeksiyon örneklerinde A.flavus ve kulak örneklerinde A.niger görüldüğü bildirilmiştir ${ }^{1}$. Çalışmamızda da benzer olarak örnekler çoğunlukla solunum yolundan alınmış olup sıklıkla A. fumigatus ürediği görülmüştür.

Geleneksel yöntemlerin gerek zaman alıcı olması, gerekse her zaman net sonuç verememeleri, bazı mantar türlerinin zor yorumlanması ve ek testlere gereksinim duyulması nedeniyle son yıllarda moleküler yöntemlere eğilim $\operatorname{artmıştır}^{1,20}$.

Moleküler yöntemlerle tanımlamada yöntemin başarısı hedeflenen dizi veya gene bağlı olarak farklılık göstermektedir. ITS1 ve ITS2 bölgesi türler arasında farklılık gösterdiği için tür ayrımında yaygın olarak kullanılmaktadır ${ }^{1,21}$.

Çalışmamızda çeşitli klinik örneklerden izole ettiğimiz Aspergillus türlerinin tümünü, ITS1ITS2 gen bölgesini hedef alarak DNA dizi analiziyle tür kompleksi düzeyinde tanımladık. Geleneksel yöntemle tanımladığımız tüm Aspergillus türlerini, DNA dizi analizi yöntemiyle karşılaştırdığımızda \%97,9 uyumlu bulduk. Geleneksel yöntemlerin başarısının değerlendiricinin bilgi ve tecrübesiyle orantılı olarak arttığı gözlemlendi.

Moleküler yöntem olarak kullanılan ITS dizi analizi, tamamlayıcı yöntem olarak 
kullanılabilir olmasının yanı sıra altın standart olarak kabul edilmektedir.

MALDI-TOF MS yönteminin temeli, mikroorganizmanın protein parmak izinin (fingerprint) çıkarılması ve bunun önceden iyi tanımlanmıș, veri tabanı oluşturulmuş kütüphanelerdeki referans spektrumlarla karşılaştırılması esasına dayanmaktadır. Tıbbi önemi olan mikroorganizmaların ayrımında ve türler arası karşılaştırmada etkili bulunmuştur ${ }^{11}$.

Alanio ve arkadaşları, MALDI-TOF MS (Bruker Daltonics) ile 140 Aspergillus türünü incelemişler ve yöntem ile $138(\% 98,6)$ izolatı doğru bir șekilde tanımlanırken 2 izolatın tanımlanması yapılmamasına rağmen yanlış tanımlanan izolat olmadığ MALDI-TOF MS (Bruker Daltonics) yönteminin özgüllüğünü \%100 olarak belirtmişlerdir 22 . Fransa'da çok merkezli yapılan bir çalışmada DNA dizi analizi baz alınarak 625 filamentöz mantar örneği, geleneksel yöntem ve MALDITOF MS yöntemi ile değerlendirilmiștir. Çalışmada 58 tür tanımlanmıştır. Doğru tanımlama oranı, geleneksel yöntemle \%80 (501 izolat) iken MALDI-TOF MS ile \%89 (556 izolat) olduğu görülmüștür. MALDI-TOF MS ile 65 izolat $(\% 10,4)$ tanımlanamazken 4 izolat $(\% 0,6)$ yanlış tanımlanmıştır. MALDI-TOF MS ile geleneksel tanımlama karşılaştırıldığında; MALDI-TOF MS'in klinik laboratuvarlarda izole edilen küflerin tanımlanmasını daha da geliştirdiği belirtilmiştir ${ }^{23}$. MALDI-TOF yöntemi ile yapılan birçok çalışmada, geleneksel yöntemlere göre daha hızlı ve güvenilir sonuçlar verdiği gösterilmiştir 5,10,14,24.

Atalay ve arkadaşlarının yaptığı benzer bir çalışmada Aspergillus türlerini tanımlama da geleneksel yöntem ile rep-PCR ve MALDI-TOF yöntemlerinde anlamlı bir uyum olduğu belirtilmiştir ${ }^{1}$.

Verwer ve arkadaşları tarafından morfolojik olarak birbirine benzer olan 16 A.fumigatus ve 16 A.lentulussuşlarını tanımlama için VITEK MS
RUO, Raman spektroskopy ve PCR yöntemlerini karșılaștıran bir çalıșma yapılmıștır. Suşları doğru tanımlama oranları Raman spektroskopy ile \%78 (25/32), PCR ve VITEK MS RUO ile \%100 oranında doğru tanımlandığg bildirilmiştir. Zaman açısından değerlendirildiğinde üç yönteme kültür zamanı eklenince tanımlanma süresi, Raman spektroskopy ile 100 saat, PCR ile 57 saat ve VITEK MS RUO ile 50 saat sürdügü görülmüştür ${ }^{25}$.

Çalışmamı ile diğer çalışmalar karşılaştırıldığında MALDI-TOF MS in doğru tanımlama yüzdesinin uyumlu olduğunu görüyoruz. Çalışmamızda geleneksel yöntem ve DNA dizileme sonuçları karşılaştırıldığında \%97,9 uyum olduğu gözlenmesine karşın MALDI-TOF MS sistemi 4 kökeni $(\% 8,3)$ tanımlayamadığı saptandı. Altın standart olarak alınan dizi analizi sonuçlarına göre MALDI-TOF MS sistemi tanımladığı 44 suștan 2'sinin $(\% 4,5)$ uyumsuz olduğu görüldü. MALDI-TOF sistemi ile tanımlaması yapılan 48 kökenin 42'si $(\% 87,5)$ geleneksel yöntem ve DNA dizi analiz sonuçları ile uyumlu geldi. Çalıșmamızda güvenilir olmayan yanlıș sonuçların nedeni; cihazı çalıştırma hataları, teknik problemler, test edilen mantarın cihazın kütüphanesinde ve veri tabanında bulunmaması, cihazın rutin kalibrasyonunun düzgün yapılmamasından kaynaklanabilir.

Sonuç olarak; geleneksel yöntem/dizileme sonuçlarının tür kompleksi düzeyinde uyumlu olduğu (geleneksel yöntem kendi sınırları içinde başarılı) ve MALDI-TOF MS'in tür düzeyinde sonuç verebilmesi nedeniyle geleneksel yönteme göre avantajlı olabileceği ancak çalışılan az sayıda suş arasında kriptik türlerin bulunmaması nedeniyle bu avantaj saptanamayabilmektedir.

MALDI-TOF MS yöntemi zaman açısından değerlendirildiğinde hızlı ve duyarlı bir yöntemdir. Ancak kullanılan cihazın daha doğru ve güvenilir sonuç vermesi için veri tabanının 
geliştirilmesi gerekmektedir. MALDI-TOF MS yönteminin veri tabanının geliştirilmesi için bu tür çalışmaların suş sayısının arttırılarak tekrarlanması gerekmektedir.

Yakın zamanda moleküler yöntemler geleneksel yöntemlerin yerini alacak gibi gözükmektedir. Fakat pahalı bir yöntem olması, tecrübeli ekipman gerektirmesi gibi nedenlerden dolayı rutin laboratuarlarda değil ancak araştırma laboratuarlarında kullanılabileceği düşünülmektedir.

Bu çalışma, 2014 yllında İstanbul Üniversitesi Cerrahpaşa Tıp Fakültesi Tıbbi Mikrobiyoloji Anabilim Dalı Uzmanlı Tezi olarak sunulmuştur.

Çıkar Çatışması Beyanı: Bu çalışmada çıkar çatışması yoktur.

Finansal Destek: $\mathrm{Bu}$ proje İstanbul Üniversitesi Bilimsel Araştırma Projeleri Fonu tarafından desteklenmiştir. Proje No: 41077

Declaration of Conflicting Interests: There is no conflict of interest in this study.

Financial Disclosure: This project was supported by Istanbul University Scientific Research Projects Fund. Project No: 41077

\section{KAYNAKLAR}

1. Atalay A, Koc AN, Suel A, et al. Conventional Morphology Versus PCR Sequencing, rep-PCR, and MALDI-TOF-MS for Identification of Clinical Aspergillus Isolates Collected Over a 2-Year Period in a University Hospital at Kayseri, Turkey. J Clin Lab Anal. 2016; 30: 745-50.

2. Gautier M, Normand AC, Ranque S. Previously unknown species of Aspergillus. Clin Microbiol Infect. 2016; 22: 662-9.

3. Sanguinetti M, Posteraro B. Identification of Molds by Matrix-Assisted Laser Desorption Ionization-Time of Flight Mass Spectrometry. J Clin Microbiol. 2017; 55: 369-79.

4. Lamoth F. Aspergillus fumigatus-Related Species in Clinical Practice.Front Microbiol. 2016; 7: 683.
5. Li Y, Wang H, Zhao YP, Xu YC, Hsueh PR. Evaluation of the Bruker Biotyper Matrix-Assisted Laser Desorption/Ionization Time-of-Flight Mass Spectrometry System for Identification of Aspergillus Species Directly from Growth on Solid Agar Media.Front Microbiol. 2017; 8: 1209.

6. Gülmez D. Aspergillus fumigatus Kompleksi: Zorlu Bir Patojende Yeni Bir Sorun, Azol Direnc. Türk Mikrobiyol Cem Derg. 2018; 48: 153-66.

7. Chalupová J, Raus M, Sedlářová $M$, Sebela M. Identification of fungal microorganisms by MALDI-TOF mass spectrometry. Biotechnol Adv. 2014; 32: 230-41.

8. Nakamura S, Sato H, Tanaka R, Yaguchi T. Verification of Ribosomal Proteins of Aspergillus fumigatus for Use as Biomarkers in MALDI-TOF MS Identification. Mass Spectrom (Tokyo). 2016; 5: A0049.

9. Pelit S, Erköse Genç G, Barış A, Erturan Z. Trichosporon Türlerinin Tanımlanmasında Matriks Aracılı Lazer Dezorpsiyon İyonizasyon-Uçuş Zamanlı-Kütle Spektrometresi (MALDI-TOF MS) Sisteminin API ID 32C ve VITEK 2 ile Karşılaştırılması. Türk Mikrobiyol Cem Derg. 2017; 47: 169-75.

10. Özcan N, Ezin Ö, Akpolat N, Mete M, Gül K. Identification of Candida species isolated from clinical specimens by MALDI-TOF MS. Dicle Medical Journal. 2016; 43: 390-4.

11. Yılmaz S, Duyan S, Artuk C, Diktaş H. Applications of MALDI-TOF MS in Microbiological Identification. TAF Prev Med Bull. 2014; 13: 421-6.

12. Vidal-Acuña MR, Ruiz-Pérez de Pipaón M, TorresSánchez MJ, Aznar J. Identification of clinical isolates of Aspergillus, including cryptic species, by matrix assisted laser desorption ionization time-of-flight mass spectrometry (MALDI-TOF MS). Med Mycol. 2018; 56: 838-46.

13. Park JH, Shin JH, Choi MJ, et all. Evaluation of matrixassisted laser desorption/ionization time-of-fight mass spectrometry for identification of 345 clinical isolates of Aspergillus species from 11 Korean hospitals: comparison with molecular identification. Diagn Microbiol Infect Dis. 2017; 87: 28-31.

14. Schulthess B, Ledermann R, Mouttet F, et all. Use of the Bruker MALDI Biotyper for identification of molds in the clinical mycology laboratory. J Clin Microbiol. 2014; 52: 2797-803.

15. Erdem İ, Doğan M, Karaali R, Omar ŞE, Ardiç E. Treatment Of Invasıve Aspergillosıs. Namık Kemal Tıp Dergisi. 2018; 6: 64-8. 
16. Birinci A, Çaycı YT. Mantar Enfeksiyonlarının Serolojik Tanısı. Türk Hijyen ve Deneysel Biyoloji Dergisi 2016; 73: 175-82.

17. Ullmann AJ, Aguado JM, Arikan-Akdagli S, et all. Diagnosis and management of Aspergillus diseases: executive summary of the 2017 ESCMID-ECMM-ERS guideline. Clin Microbiol Infect. 2018; 24 (Suppl1) e1e38.

18. Sleiman S, Halliday CL, Chapman B, et al. Performance of Matrix-Assisted Laser Desorption Ionization-Time of Flight Mass Spectrometry for Identification of Aspergillus, Scedosporium, and Fusarium spp. in the Australian Clinical Setting. J Clin Microbiol. 2016; 54: 2182-6.

19. Liao Y, Chen M, Hartmann T, Yang RY, Liao WQ. Epidemiology of opportunistic invasive fungal infections in China: review of literature. Chin Med J (Engl). 2013; 126: 361-8.

20. Aslan M, Öz Y, Akșit F, Akay MO. İnvaziv Fungal Enfeksiyonların Tanısında In-House Polimeraz Zincir Reaksiyonunun Değerlendirilmesi. Osmangazi Tıp Dergisi/Osmangazi Journal of Medicine. 2016; 38: 2631.
21. Alshareef F, Robson GD. Prevalence, persistence, and phenotypic variation of Aspergillus fumigatus in the outdoor environment in Manchester, UK, over a 2-year period. Med Mycol. 2014; 52: 367-75.

22. Alanio A, Beretti J-L, Dauphin B, et all. Matrix-assisted laser desorption ionization time-of-flight mass spectrometry for fast and accurate identification of clinically relevant Aspergillus species. Clin Microbiol Infect. 2011; 17: 750-5.

23. Ranque $\mathrm{S}$, Normand AC, Cassagne $\mathrm{C}$, et all. MALDITOF mass spectrometry identification of filamentous fungi in the clinical laboratory. Mycoses. 2014; 57: 13540.

24. Bader O. MALDI-TOF-MS-based species identification and typing approaches in medical mycology. Proteomics. 2013; 13: 788-99.

25. Verwer PE, van Leeuwen $W B$, Girard $V$, et all. Discrimination of Aspergillus lentulus from Aspergillus fumigatus by Raman spectroscopy and MALDI-TOF MS. Eur J Clin Microbiol Infect Dis. 2014; 33: 245-51. 